\title{
Plant pathogen-induced volatiles attract parasitoids to increase parasitism of an insect vector
}

\author{
Xavier Martini, Kirsten S. Pelz-Stelinski and Lukasz L. Stelinski* \\ Entomology and Nematology Department, Citrus Research and Education Center, University of Florida, Lake Alfred, FL, USA
}

\section{Edited by:}

Juergen Gross, Julius Kühn-Institut, Germany

Reviewed by:

Charles Linn, Cornell University, USA

Cesar Rodriguez-Saona, Rutgers University, USA

\section{${ }^{*}$ Correspondence:}

Lukasz L. Stelinski, Entomology and Nematology Department, Citrus Research and Education Center, University of Florida,

700 Experiment Station Road, Lake

Alfred, FL 33850, USA

e-mail:stelinski@ufl.edu

Interactions between plant pathogens and arthropods have been predominantly studied through the prism of herbivorous arthropods. Currently, little is known about the effect of plant pathogens on the third trophic level. This question is particularly interesting in cases where pathogens manipulate host phenotype to increase vector attraction and presumably increase their own proliferation. Indeed, a predator or a parasitoid of a vector may take advantage of this manipulated phenotype to increase its foraging performance. We explored the case of a bacterial pathogen, Candidatus Liberibacter asiaticus (Las), which modifies the odors released by its host plant (citrus trees) to attract its vector, the psyllid Diaphorina citri. We found that the specialist parasitoid of D. citri, Tamarixia radiata, was attracted more toward Las-infected than uninfected plants. We demonstrated that this attractiveness was due to the release of methyl salicylate. Parasitization of $D$. citri nymphs on Las-infected plants was higher than on uninfected controls. Also, parasitization was higher on uninfected plants baited with methyl salicylate than on non-baited controls. This is the first report of a parasitoid "eavesdropping" on a plant volatile induced by bacterial pathogen infection, which also increases effectiveness of host seeking behavior of its herbivorous vector.

Keywords: plant pathogens, parasitoids, tri-trophic interactions, semiochemicals, huanglongbing

\section{INTRODUCTION}

There is mounting evidence that vector borne pathogens manipulate the behavior of their vectors by altering the state of the vector's host. This occurs in both plant-pathogen-vector interactions (Ngumbi et al., 2007; Mauck et al., 2010; Davis et al., 2012; Mann et al., 2012), as well as, in animal-pathogen-vector systems (Rogers and Bates, 2007; van den Abbeele et al., 2010; Cornet et al., 2013). This manipulation of vector behavior is indirect, in that the pathogens alter their host so as to render them more attractive (Ngumbi et al., 2007; Cornet et al., 2013) and in some cases also less nutritious (Mauck et al., 2010; Davis et al., 2012; Mann et al., 2012) to vectors as compared with non-infected counterparts. Pathogen infection can either increase the overall amount of odorants released by an infected host or change the qualitative composition of chemicals released by up-regulating the release of certain specific odorants; both mechanisms have been found to explain manipulation of vector behavior (Eigenbrode et al., 2002; McLeod et al., 2005; Mauck et al., 2010; Davis et al., 2012; Mann et al., 2012). Also, changes in host quality as a food resource following infection can influence vector behavior (Mauck et al., 2012).

In plant systems, simultaneous manipulation of both plant odorant release and nutritional quality may result in initial attraction of herbivores to nutritionally sub-optimal, pathogeninfected plants followed by subsequent dispersal to and setting on nutritionally superior, non-infected counterparts (Mauck et al., 2010; Davis et al., 2012; Mann et al., 2012). This mechanism may drive pathogen spread throughout a community of plant hosts and has been termed the "deceptive host phenotype hypothesis" (Mauck et al., 2010).
Recent literature syntheses and data have highlighted how plant pathogens shape arthropod communities through their impact on plant phenotype (Tack et al., 2012; Biere and Tack, 2013; Tack and Dicke, 2013). Despite the focus on three-way interactions between pathogen, host (plant), and vector (herbivore) in several investigations, there is still little information regarding the effect of plant pathogens on the third trophic level. This necessitates investigations beyond two-way interactions and a focus on multiple interactions simultaneously as depicted in Tack and Dicke (2013), Guerrieri et al. (2004) found that the parasitoid, Aphidius ervi Haliday, preferred tomato plants with roots colonized by the arbuscular mycorrhizal fungus Glomus mosseae Nicol \& Gerd as compared with non-infested roots. Conversely, Pineda et al. (2013) showed that the non-pathogenic rhizobacterium, Pseudomonas fluorescens Migula, modifies the odorant blend released by Arabidopsis thaliana (L.) Hygne, and that this modified blend is less attractive to the aphid parasitoid, Diaeretiella rapae McIntosh. These examples illustrate the possibility that microbes, including pathogens, can also affect the foraging behavior of natural enemies.

There is some evidence that plant fungal pathogens can affect the behavior of insects at the third trophic level. For instance, peanut plants infected with the white mold fungus, Sclerotium rolfsii Saccardo, and simultaneously damaged by the beet armyworm, elicit greater attraction of the armyworm's wasp parasitoid, Cotesia marginiventris Cresson, than plants damaged by beet armyworm without fungus (Cardoza et al., 2003). In this example, pathogen and herbivore infection/infestation needed to occur simultaneously to affect behavior of the parasitoid. Another example is the leafminer, Tischeria ekebladella Bjerkander, which 
exhibits greater parasitism on mildew-infected than uninfected oak leaves (Tack et al., 2012). However, fungal infection of plants does not always affect parasitoid host choice (i.e., Rostàs et al., 2006). We postulated that in cases where a pathogen manipulates the odor(s) released by its host so as to attract its vector for possible increased proliferation, this manipulation might also attract natural enemies of the vector, such as parasitoids.

In insect-transmitted plant pathogen systems, there are a number of examples describing virus-mediated (Eigenbrode et al., 2002; Mauck et al., 2012; Shapiro et al., 2012) or bacteriamediated (Shapiro et al., 2012) effects on plants that in turn affect vector behavior. There is also a recent example congruent with the deceptive host phenotype hypothesis that involves the bacterial pathogen, Candidatus Liberibacter asiaticus (Las), of citrus (Mann et al., 2012). Infection of citrus plants with this pathogen causes induced release of a plant defense volatile, methyl salicylate (MeSA), which specifically attracts the herbivorous insect vector, Asian citrus psyllid (Diaphorina citri Kuwayama). Within the tree, the Las pathogen causes huanglongbing (HLB), an incurable, deadly disease that threatens commercial citrus industries worldwide (Grafton-Cardwell et al., 2013).

Infected citrus plants are initially preferred by the vector over uninfected plants because of induced release of MeSA (Mann et al., 2012). However, infected plants are nutritionally suboptimal, as compared with uninfected plants, which may be detected by the vector during feeding, causing it to subsequently leave infected plants and settle on nearby uninfected plants after successful acquisition of the pathogen (Mann et al., 2012). Coincidentally, MeSA is released at the same relative release rate (per area of plant) following both plant infection by the Las bacterial pathogen and following feeding damage by the psyllid vector on uninfected plants (Mann et al., 2012). Therefore, an insect-induced plant defense cue (MeSA), used by the psyllid vector as an infochemical for mate rendezvous on a fleeting host resource (new leaf flush), may also be exploited by a pathogen. The pathogen also induces release of this same cue at the same release rate so as to attract vectors to infected plants as a possible mechanism for enhancing its own spread (Mann et al., 2012).

In the citrus system described above, the lifecycle of $D$. citri is limited by availability of newly ( $0-4$ days post bud break) unfurled leaf flush, which is the only possible site for egg laying for successful nymph development and eventual emergence of the subsequent adult generation (Grafton-Cardwell et al., 2013). The pathogen vector ( $D$. citri) is effectively parasitized by an ectoparasitoid wasp, Tamarixia radiata Waterston (Eulophidae). This parasitoid wasp may be an important factor for regulating populations of D. citri (Grafton-Cardwell et al., 2013). Female T. radiata are closely associated with their insect herbivore host and have evolved to specifically hone in on the volatiles released by the immature nymphal stages of $D$. citri (Mann et al., 2010). Considering multiple interactions simultaneously, our question was whether a specific pathogen (bacterium)-induced cue from a plant, which deceptively attracts insect vectors to infected plants, could also simultaneously serve as an infochemical to attract a parasitoid "bodyguard of the plants" (Biere and Tack, 2013) that specializes on this herbivore (Figure 1). This type of parasitoid eavesdropping on pathogen-induced volatiles may counteract the impact of pathogen-induced manipulation of vector behavior as a mechanism for pathogen spread between hosts and therefore should be considered as part of a more complete ecosystem view. It is initially easy to assume that pathogen-mediated vector attraction to infected plants may lead to increased spread of pathogen, but this may be complicated by several factors, including the impact of parasitoids and predators (Biere and Tack, 2013).

In the current investigation, we explored whether the parasitoid wasp, T. radiata, "eavesdrops" on plant volatiles induced

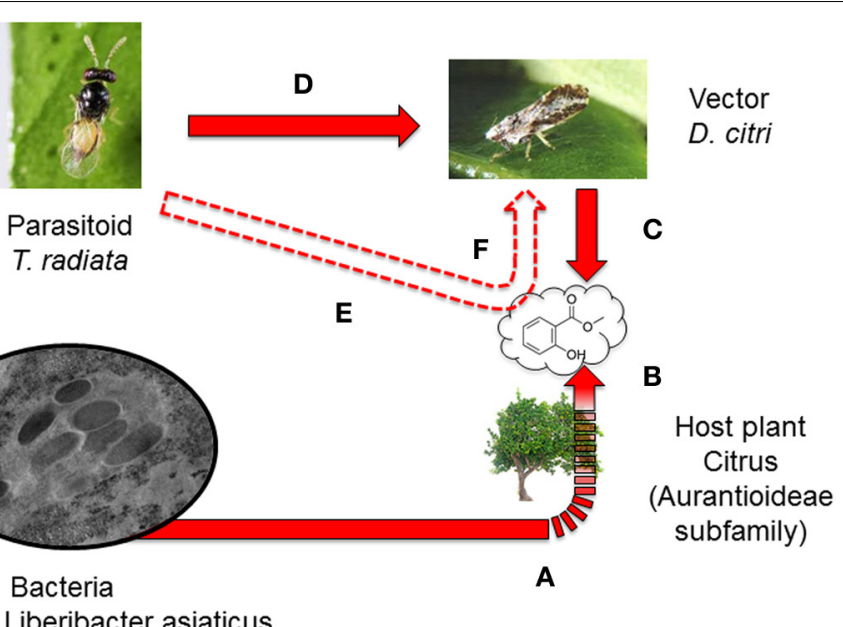

Candidatus Liberibacter asiaticus

FIGURE 1 | The hypothetical effects of the phytopathogenic bacterium, Candidatus Liberibacter asiaticus (Las), on the behavior of the parasitoid, Tamarixia radiata. Las manipulates the citrus phenotype by: (a) changing the odor profile with increased release of methyl salicylate (b) and consequently causing infected plants to be more attractive to the Las vector Diaphorina citri, than uninfected counterparts (c). We hypothesized that $T$. radiata, a known parasitoid of $D$. citri, that is attracted to volatiles released by the immature nymphal stages of $D$. citri (d) may also be more attracted to this pathogen modified odor release (e) and consequently increase parasitism on D. citri (f). Plain red arrows indicate known and documented interactions in this system. Dashed red arrows indicate potential interactions that are the focus of our study. 
by a bacterial pathogen (Las) of citrus to improve location of its insect herbivore host. We demonstrated that the wasp parasitoids prefer the volatiles released from infected plants over those from non-infected counterparts in two-choice assays, mirroring the previously documented behavior of its host (D. citri), the herbivorous vector of the Las pathogen. We also found that the dosage of the specific induced volatile (MeSA) that manipulates behavior of the herbivore also attracts the parasitoid and consequently increases parasitization and associated mortality of the insect pathogen vector.

\section{MATERIALS AND METHODS INSECT CULTURES}

Tamarixia radiata adults were reared on $D$. citri that were maintained on Murraya paniculata L. (Jack). Insects were reared in a greenhouse and maintained at $25-27^{\circ} \mathrm{C}, 60-80 \%$ R.H., and $14 \mathrm{~L}$ : $10 \mathrm{D}$ photoperiod. Adult wasps of both sexes were maintained in $40 \times 40 \times 40 \mathrm{~cm}$ Plexiglas cages at $26 \pm 1^{\circ} \mathrm{C}, 60 \pm 5 \%$ R.H., under 14L: $10 \mathrm{D}$ photoperiod and provided with $25 \%$ sugar solution in a plastic cup with protruding cotton wick. Female wasps used for experiments were presumably mated following at least 5-12 days of maintenance in cages prior to assays. Psyllids used for rearing wasps and experiments were obtained from a culture established in 2000 from field populations in Polk Co., FL, USA $(28.0$ 'N, $81.9^{\prime} \mathrm{W}$ ) prior to the discovery of HLB in the state. This culture is maintained on sour orange (Citrus aurantium L.) and "Hamlin" orange (Citrus sinensis L.) seedlings with flush [immature leaves as described in Hall and Albrigo (2007)] in a greenhouse at $27-28^{\circ} \mathrm{C}, 60-65 \%$ R.H., and 14L: 10D photoperiod.

\section{PLANTS}

Las infection in host plants was induced by graft-inoculation of non-infected $C$. sinensis with Las-infected key lime (Citrus aurantifolia Swingle) budwood collected from citrus groves in Immokalee, FL, USA. Leaf samples from grafted plants were tested for Las infection by qPCR 6 months after grafting, as described below. Plants that tested positive for Las were used in experiments and for maintenance of Las cultures. Cultures of Las-infected plants were maintained through graft-inoculations because of low transmission efficiency of $D$. citri adults (Mann et al., 2012). Given that Las is not seed transmissible, uninfected plants used in experiments were cultivated from $C$. sinensis seed or obtained as potted seedlings from a certified HLB-free commercial nursery to minimize the risk of undetectable latent infection of Las in grafted plants (Mann et al., 2012). The nursery-obtained plants were confirmed negative for Las infection by $\mathrm{qPCR}$ as described below. All infected plants used for experiments exhibited minor or no symptoms, ranging from 0 to 1 on a graded symptom scale of 1 to 10 (Mann et al., 2012). Non-infected and Las-infected plants were maintained in separate secure rearing facilities with minimal risk of cross contamination under the environmental conditions described above for insects.

\section{DETECTION OF LAS IN PLANT SAMPLES}

Dual-labeled probes were used to detect Las in citrus plants using an ABI 7500 system (Applied Biosystems, Foster City, CA) in a multiplex TaqMan qPCR assay described in Li et al. (2006) and Pelz-Stelinski et al. (2010). DNA from leaf samples was isolated using DNeasy plant kits (Qiagen Inc, Valencia, CA). Lasspecific $16 \mathrm{~S}$ rDNA from plant extracts was amplified using probeprimer sets targeting internal control sequences specific to plant [cytochrome oxidase] gene regions (Li et al., 2006; Pelz-Stelinski et al., 2010).

DNA amplifications were conducted in 96-well MicroAmp reaction plates (Applied Biosystems). Quantitative PCR reactions consisted of an initial denaturation step of $95^{\circ} \mathrm{C}$ for $10 \mathrm{~min}$ followed by 40 cycles of $95^{\circ} \mathrm{C}$ for $15 \mathrm{~s}$ and $60^{\circ} \mathrm{C}$ for $60 \mathrm{~s}$. Each 96 -well plate included a no template control, a positive control (Las DNA in DNA extractions from plant), and a negative control (no Las DNA in DNA extractions from plant). Reactions were considered positive for either target sequence if the cycle quantification $(\mathrm{Cq})$ value, determined by the ABI 7500 Real-Time software (version 1.4, Applied Biosystems), was $\leq 32$ (Pelz-Stelinski et al., 2010).

\section{Y-TUBE OLFACTOMETER BEHAVIORAL ASSAY}

The Y-tube olfactometer consisted of a 14-cm long stem and two $10 \mathrm{~cm}$ long arms, each with a $2-\mathrm{cm}$ inner diameter (Mann et al., 2010). A screened glass plug at the base of the stem was used to introduce insects into the Y-tube. To ensure chemical free ambient air supply, both arms of the olfactometer received charcoal purified and humidified air from a custom made air delivery system (ARS, Gainesville, FL). A constant airflow of $0.11 \mathrm{~min}^{-1}$ was maintained through both arms of the olfactometer. Depending on experiment, the Y-tube olfactometer was positioned horizontally or vertically [the position of the olfactometer has no impact on T. radiata choice (Mann et al., 2010)] under a fluorescent 1600 lux light source (GE Lighting, Cleveland, $\mathrm{OH}$ ) mounted within a $1.0 \times 0.6 \times 0.6 \mathrm{~m}$ fiber board box for uniform light diffusion. The measured light intensity was $\sim 700$ lux throughout the entire Ytube. Female T. radiata adults were released individually $(n=40)$ at the base of the Y-tube and allowed $300 \mathrm{~s}$ to exhibit a behavioral response. The number of wasps leaving the release point was recorded. A positive response was recorded when a wasp moved from the stem and entered into either arm of the olfactometer. Those wasps that did not leave the stem of the Y-tube were designated as non-responders. All assays were conducted at $26 \pm 1^{\circ} \mathrm{C}$ and $60 \pm 2 \% \mathrm{RH}$.

\section{EXPERIMENT 1: WASP RESPONSE TO VOLATILES FROM INFECTED VS. UNINFECTED PLANTS}

The objective of this series of experiments was to test the hypothesis that infection of citrus with the Las bacterium alters wasp behavior in response to host plant volatiles. Since $D$. citri feeding damage induces release of plant defense volatiles that is remarkably similar to that observed following Las infection (Mann et al., 2012), an associated hypothesis tested was that psyllid feeding damage to plants alters wasp response to damaged vs. undamaged plants. In this series of experiments, $D$. citri adults were used to induce volatile release from damaged plants. T. radiata are attracted to volatiles from $D$. citri nymphs, but not adults (Mann et al., 2010). Therefore, using D. citri adults allowed us to induce citrus volatiles without the confounding effect of headspace volatiles from nymphs that are attractive to $T$. radiata. Prior to odor testing, T. radiata adults were exposed to 
clean air vs. clean air in the olfactometer to verify the absence of positional bias. Thereafter, the following odor source combinations were tested: (1) infected plants vs. uninfected plants, (2) uninfected plants receiving psyllid adult feeding damage vs. uninfected plants with no psyllid damage, (3) uninfected plants receiving psyllid adult feeding damage vs. infected plants receiving psyllid adult feeding damage, and 4) adult psyllids with no plants vs. a blank odor control. Plant samples were placed into $35 \mathrm{~cm}$ tall $\times 15 \mathrm{~cm}$ wide dome-shaped (5l volume) volatile collection chambers from Analytical Research Systems (Gainesville, FL) as described in Mann et al. (2011). For the feeding damage treatment, 50 adult male and 50 adult female D. citri were placed onto plants for $24 \mathrm{~h}$ prior to assays. This duration of feeding damage has been proven sufficient to produce a release of herbivore-induced volatiles from citrus plants (Mann et al., 2012). For the treatment in which wasps were challenged with odors from psyllids without plants, 50 male and 50 female adults were placed into otherwise empty chambers. For a blank odor control treatment, chambers were left empty.

The olfactometer arms were connected to odor sources placed in the volatile collection chambers through Teflon glass tube connectors (Mann et al., 2011). The chambers containing treatments were attached to inlet and outlet valves for incoming and outgoing air streams, respectively. Purified and humidified air was pushed through these chambers via two pumps connected to an air delivery system (ARS, Gainesville, FL). Odor sources were randomly assigned to one arm of the olfactometer at the beginning of each bioassay and were reversed every five insects to eliminate positional bias. Different sets of plant treatments were used every 10 females, resulting in four replicates of 10 females $(n=40$, including non-responders).

\section{EXPERIMENT 2: WASP RESPONSE TO SYNTHETIC ODOR SOURCES}

The objective of this experiment was to determine whether MeSA is attractive to T. radiata. MeSA release is induced by both Las infection and $D$. citri feeding damage at approximately 10-13 ng / plant/ 24 h (Mann et al., 2012). Two known attractants of $D$. citri, $\beta$-ocimene and D-limonene (Patt and Setamou, 2010; Mann et al., 2012), were used as additional controls for wasp behavior to explore the specificity of MeSA as an attractant. All chemicals were obtained from Sigma Aldrich (St Louis, MO) with approximately $97-99 \%$ purity for MeSA and D-limonene. Purity of $\beta$-ocimene was $\geq 90 \%$ and contained a mixture of isomers comprising 20-25\% limonene. MeSA was dissolved in $100 \mu \mathrm{l}$ of dichloromethane and pipetted onto $2 \mathrm{~cm}$ Richmond cotton wicks (Petty John Packaging, Inc. Concord, NC) at 0.001, 0.01, $0.1 \mu \mathrm{g}$ dosages. This dosage range was chosen because the $0.01 \mu \mathrm{g}$ dosage of MeSA has been found to attract the $D$. citri host of $T$. radiata and causes a release rate from the synthetic lure that approximates the release of MeSA from citrus plants caused by Las infection or caused by active damage to citrus plants by $D$. citri adult feeding (Mann et al., 2012). $\beta$-Ocimene and D-limonene treatments were prepared the same way, but at 1.0 and $100 \mu \mathrm{g}$ dosages, respectively, because these are the lowest dosages known to attract D. citri under the same conditions, with this type of laboratory olfactometer (Mann et al., 2012). The control treatment in each case consisted of a cotton wick impregnated with solvent only. The solvent from both treatments and controls was allowed to evaporate within a fume hood for $30 \mathrm{~min}$ prior to assays.

The bioassay procedures with synthetic chemicals were nearly identical to those described earlier for plant samples, except that the assay differed slightly in that odor sources were placed into straight glass tubes $(17.5 \mathrm{~cm}$ long $\times 3.5 \mathrm{~cm}$ wide $)$ supported with an inlet and outlet valve for incoming and outgoing air streams, connected to two olfactometer arms through Teflon-glass tube connectors (Mann et al., 2011). Movement of wasps from the olfactometer into the connecting tubes was restricted by a metal mesh filter, which was glued to the connecting tube. Odors were pushed through the olfactometer arms using purified and humidified air via two pumps connected to the air delivery system (ARS, Gainesville, FL). Odor sources were randomly assigned to one arm of the olfactometer at the beginning of each bioassay and were reversed every five insects to eliminate positional bias. Cotton wicks impregnated with chemicals were newly prepared every 10 females, resulting in four replicates of 10 females ( $n=40$, including non responders).

\section{EXPERIMENT 3: EFFECT OF LAS INFECTION AND MESA LURE ON PARASITIZATION OF D. CITRI BY T. RADIATA}

The objective of this experiment was to determine whether parasitization frequency of $D$. citri nymphs by T. radiata is affected by the pathogen infection status of the insect herbivore's host plant, and if this effect is mediated by MeSA. Two citrus plants were placed randomly into $0.35 \times 0.35 \times 0.6 \mathrm{~m}$ observation cages (Bioquip Products, Rancho Dominguez, CA). For each assay, four replicate cages were established. The cages were housed under temperature-controlled conditions of $27 \pm 1^{\circ} \mathrm{C}, 63 \pm 2 \%$ $\mathrm{RH}$, and under a 14L: 10D photoperiod. These conditions were established to maximize parasitism (Gomez-Torres et al., 2012). Twenty fourth instar $D$. citri nymphs were placed onto each plant per replicate using a camel hair brush. Nymphs were placed onto newly developing leaf flush as defined in Hall and Albrigo (2007) and allowed $24 \mathrm{~h}$ of acclimation before wasps were released. $D$. citri nymphs crawl within individual leaf flush, but are unable to move between flush within a tree (Grafton-Cardwell et al., 2013). The base of the stem upon which nymphs were released was marked with black marker to facilitate finding of the psyllid(s) after $24 \mathrm{~h}$. After nymph acclimation, a single female T. radiata was released per replicate cage and allowed to potentially parasitize psyllids for $24 \mathrm{~h}$. Adult female T. radiata are capable of laying up to 300 eggs per lifetime (Étienne et al., 2001).

Each cage received $25 \%$ sugar water solution for wasps as described above. After $24 \mathrm{~h}$, all nymphs that could be found were isolated directly on the flush with nylon mesh bags as described in Stelinski et al. (2010) to prevent possible further contact with wasps. The parasitization of $D$. citri on each Las-infected or non-infected citrus plant was recorded $14 \mathrm{~d}$ after initial possible exposure to wasps given that egg to adult length of development for T. radiata is completed after this duration under these experimental conditions (Gomez-Torres et al., 2012). A sample was scored as parasitized if a $D$. citri nymph was found dead with a characteristic wasp emergence hole as pictured in Étienne et al. (2001). Lack of parasitization was confirmed by emergence of 
adult $D$. citri within mesh bags. At the end of the experiment, some nymphs were not found and consequently excluded from the analysis.

The first assay consisted of testing the effect of Las infection on parasitization. Consequently, one infected and one uninfected plant, as described above, was introduced into each cage. The objective of the second assay was to determine whether parasitization frequency of $D$. citri nymphs could be altered by deployment of MeSA lures. Two uninfected citrus plants (confirmed by qPCR) were placed randomly into observation cages as described above. Within each cage, one of the two citrus plants was randomly assigned a MeSA lure treatment and the other was left untreated. Treated plants received one cotton wick dispenser treated with $0.01 \mu \mathrm{g}$ of MeSA as described above. This dosage was chosen because it resulted in the highest wasp response in previous Ytube tests (see Results). The treated wick was attached to the trunk of plants with aluminum wire at mid-plant height.

\section{STATISTICAL ANALYSES}

For the Y-tube olfactometer assays (experiments 1 and 2), we performed chi-squared tests on the pooled value of the four replicates. Beforehand, we carried out heterogeneity chi-squared tests to ensure that data from each replicate were homogenous (Zar, 2009). Wasp response data obtained per replicate (each replicate consisted of 10 wasps tested per pair of plants or cotton wick treatments) were found to be homogenous because the sum of the individual chi-squares for each replicate was not significantly different at $\alpha>0.10$ from the overall chi-squared of the pooled data (Zar, 2009). In this case, pooling the data to perform an overall chi-squared was justified (Zar, 2009). Regarding experiment 3, we compared the number of parasitized vs. unparasitized D. citri per plant with generalized linear mixed models (GLMMs) with a binomial distribution, using the statistical software R v 3.02 (The R foundation for statistical computing, Vienna, Austria). We used the infection status of the plant or the presence of the lure as the fixed variables, and the number of replicates as the random variable. GLMMs were performed with the function "lmer" of the package "lme4" (http://cran.r-project.org/web/packages/ lme4/index.html) in R.

\section{RESULTS}

\section{EXPERIMENT 1: WASP RESPONSE TO VOLATILES FROM INFECTED vS.} UNINFECTED PLANTS

Las-infected plants were more attractive to $T$. radiata than uninfected counterparts $\left(\chi^{2}=9.76\right.$, d.f. $=1, P=0.002$, Figure 2$)$. Similarly, uninfected plants that received damage by feeding $D$. citri adults were more attractive to $T$. radiata than uninfested controls $\left(\chi^{2}=25.00\right.$, d.f. $=1, P<0.001$, Figure 2$)$. The odors of adult $D$. citri, in the absence of plants and/or plant damage, did not attract $T$. radiata as compared with blank odor controls $\left(\chi^{2}=0.03\right.$, d.f. $=1, P=0.857$, Figure 2$)$. Finally, Las-infected plants infested with $D$. citri were not more attractive than uninfected plants also infested with $D$. citri adults $\left(\chi^{2}=0.12\right.$, d.f. $=$ $1, P=0.732$, Figure 2).

\section{EXPERIMENT 2: WASP RESPONSE TO SYNTHETIC ODOR SOURCES}

MeSA was attractive to $T$. radiata at the $0.01 \mu \mathrm{g}$ dosage $\left(\chi^{2}=\right.$ 11.76 , d.f. $=1, P<0.001)$, but not at the $0.1 \mu \mathrm{g}\left(\chi^{2}=0.93\right.$, d.f. $=1, P=0.336)$ or $0.001 \mu \mathrm{g}\left(\chi^{2}=2.79\right.$, d.f. $\left.=1, P=0.094\right)$ dosages as compared with the responses to solvent negative controls (Figure 2). Also, T. radiata were not attracted by either $\beta$-ocimene or D-limonene treatments, at dosages known to be attractive to $D$. citri $\left(\chi^{2}=0.04\right.$, d.f. $=1, P=0.835 ; \chi^{2}=0.03$, d.f. $=1, P=0.853$; respectively), as compared with the solvent negative controls (Figure 2 ).

\section{EXPERIMENT 3: EFFECT OF LAS INFECTION AND MESA LURE ON PARASITIZATION OF D. CITRI BY T. RADIATA}

The number of nymphs that were not found during the experiment on Las-infected vs. uninfected (control) trees was not

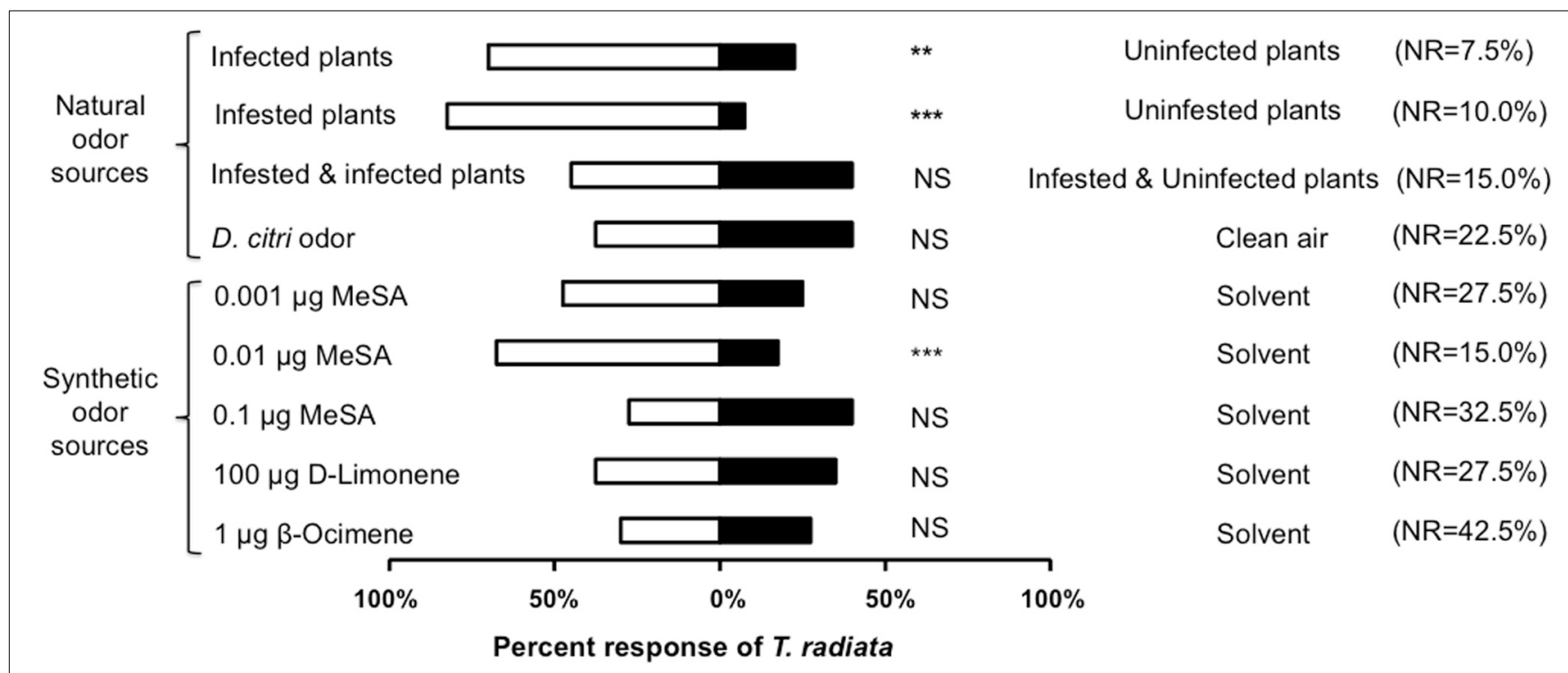

FIGURE 2 | Percentage of Tamarixia radiata responding to natural or synthetic odorants vs. blank or solvent negative controls, respectively, within a Y-tube olfactometer. NR: Percent of non-responders, $n=40$. Asterisks indicate significant differences between the two treatments $\left.{ }^{* *} P<0.01,{ }^{* * *} P<0.001\right)$. 


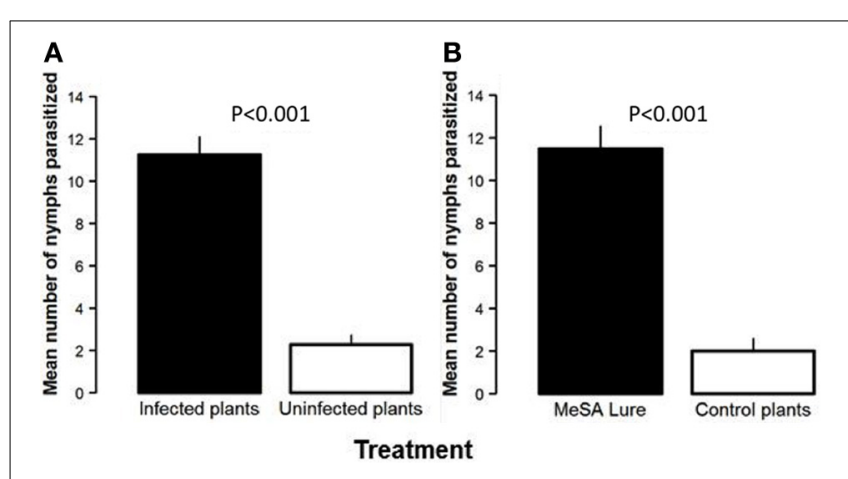

FIGURE 3 | Number of Diaphorina citri nymphs parasitized by Tamarixia radiata on: Las-infected vs. uninfected plants (A) or on uninfected plants treated with a methyl salicylate (MeSA) lure vs. uninfected plants left untreated (B).

different ( $2.50 \pm 0.29$ and $2.75 \pm 0.48$, respectively). Similarly, the number of nymphs that were not found between MeSA-treated vs. control trees was not different $(3.00 \pm 0.40$ and $3.25 \pm 0.25$, respectively). Significantly more $D$. citri nymphs were parasitized on Las-infected plants than on paired uninfected control plants in direct choice assays (Estimate $=-2.37, S E=0.43, z=-5.48$, $P<0.001$, Figure 3A). In addition, treatment of uninfected citrus plants with a synthetic MeSA lure significantly increased parasitization of $D$. citri nymphs by $T$. radiata as compared with otherwise identical uninfected plants that were not treated in this manner (Estimate $=-2.50, S E=0.42, z=-5.91, P<0.001$, Figure 3B).

\section{DISCUSSION}

It is well known that plants infested by herbivores release induced volatiles that are exploited by parasitoids or predators (Turlings and Wäckers, 2004). Organisms within the third trophic level may benefit from these orientation cues that improve location of their prey or hosts (Turlings and Wäckers, 2004). These cues may improve foraging success by natural enemies and increase their parasitization and/or predation efficiencies. Presumably, induction of volatile release as a result of pathogen infection serves as a mechanism to attract mobile vectors and consequently may result in greater proliferation of pathogen among plants. Interestingly, we demonstrated that this is not a "private communication channel," and that the cue exploited by the pathogen to attract the vector may also be used by associated parasitoids to locate their prey.

This study may be the first demonstration that a parasitoid exploits a phytopathogen-induced volatile to increase parasitization of an herbivorous pathogen vector. Congruent with our initial hypothesis (Figure 1), T. radiata wasps were attracted by volatiles emitted by Las-infected citrus plants, as compared with uninfected citrus plants. Also, Las infection caused approximately a five-fold increase in $D$. citri nymph parasitization on infected plants by wasps as compared with that observed on uninfected plants. When wasps were simultaneously presented with odors of two psyllid-infested plants (one infected with pathogen and the other uninfected), they did not exhibit a behavioral preference. This suggests that simultaneous pathogen infection and herbivore-induced damage did not increase attractiveness of citrus plants to the wasp parasitoids additively as compared with either factor alone. However, in the absence of herbivores, pathogen infection appears to essentially mimic the effect of herbivore damage with respect to attraction of the vector's parasitoid. A field investigation will be needed to complement these laboratory results and could further elucidate whether T. radiata parasitize more $D$. citri nymphs on Las-infected than on uninfected citrus plants.

Release of MeSA may explain enhanced attractiveness of Lasinfected, as compared with uninfected, plants to T. radiata wasps. MeSA release is induced in citrus by infection with Las or by $D$. citri feeding damage (Mann et al., 2012), and we found that MeSA was attractive to $T$. radiata in the currently described behavioral assays. Also, lures that released MeSA caused increased parasitization of D. citri by T. radiata on uninfected and MeSA-baited plants at a rate nearly identical to that observed as a result of Las infection. MeSA is a ubiquitous compound found in leaves of many plant species, and its emission is induced by herbivore damage or pathogen infection (Rodriguez-Saona et al., 2011). MeSA is attractive to some natural enemies of herbivores, including parasitoids [ $45 \%$ of investigations included in a recent meta-analysis by Rodriguez-Saona et al. (2011)], but can also be either neutral or even repellent (e.g., Snoeren et al., 2010). In the currently described system, MeSA is also an attractant for the D. citri vector (Mann et al., 2012) and may indicate to psyllids the presence of a suitable host, and/or the presence of conspecifics to favor mating and reproduction. It is possible that MeSA is not the only induced chemical affecting the behavior of $T$. radiata in this system and further work to address potential blends is needed.

How such a system evolved is an intriguing question. One hypothesis is that there is selection pressure for parasitoids or predators to also develop attraction to the same pathogeninduced cue(s) that attract their hosts as a form of eavesdropping to increase their foraging success. It is intriguing, for instance, that the dosage that resulted in the highest wasp response in the Y-tube olfactometer assays is the same dosage that maximally attracts the D. citri vector under the same experimental conditions (Mann et al., 2012). It suggests evolution of the wasp parasitoids' attraction to the same plant cue used by its prey in order to improve foraging efficiency. An alternative hypothesis may be that by mimicking the plant's response to psyllid damage, as a mechanism to attract conspecific vectors, the pathogen also incidentally attracts natural enemies that have already evolved attraction to these cues as a result of honing in on the herbivore-induced plant volatiles.

It is also interesting to consider whether the enhanced attraction of this parasitoid to Las-infected plants impacts proliferation of pathogen by the vector within a multi-trophic community. Theoretical and empirical data would suggest that reduction of vectors by a predator or parasitoid could decline the impact of pathogen on a community of hosts (Landis and van der Werf, 1997; Schröder and Basedow, 1999; Moore et al., 2009; Okamoto and Amarasekare, 2012). Additionally, we found that T. radiata may be attracted to infected plants before the arrival of $D$. citri or before the density of prey needed to induce feeding damage response. This may occur on plants that were previously infected by the psyllid vectors, but which are subsequently not infested 
by psyllids. Therefore, the pathogen-induced cue may cause preemptive or "early" arrival (sensu Brown, 2011) of the parasitoids, prior to subsequent infestation by more herbivores. This could favor biological control of $D$. citri on Las-infected trees as compared with uninfected counterparts. For instance, "early arrival" of predators has been described as an important prerequisite for efficient biological control of aphids (Landis and van der Werf, 1997; Brown, 2011), and this control of aphids by early arriving predators has been associated with the reduction of an aphidstransmitted virus (Landis and van der Werf, 1997). In contrast, the arrival and presence of predators or parasitoids may counter intuitively increase the spread of pathogen by causing herbivores to disperse (Finke, 2012).

Additionally, T. radiata parasitoids only attack nymphs of $D$. citri. Therefore, $D$. citri females would need to deposit eggs on infected plants in order for the wasps to eventually encounter psyllid nymphs. However, infected plants are nutritionally suboptimal to D. citri, as compared with uninfected plants, and a proportion of adult psyllids leave infected plants after initial colonization and soon after pathogen acquisition, if uninfected plants are nearby (Mann et al., 2012). Thus, these dispersing vectors may not colonize infected plants sufficiently long so as to result in egg laying. For instance in a related system, the potato psyllid, Bactericera cockerelli Sulc, prefers to oviposit on uninfected potato plants as compared with Candidatus Liberibacter solanacearuminfected potato plants (Davis et al., 2012). If this type of behavior should also occur with $D$. citri, the pathogen-induced volatiles released by plants would not only "deceive" the psyllid vector of the pathogen, but also their associated parasitoids, as they would find fewer potential hosts on infected than on uninfected plants. Specifically, both vector and parasitoid behavior would be altered to further benefit spread of the pathogen. Further modeling, based on field research, will be needed to unravel these possible counteracting forces that may shape spread of plant phytopathogens in the context of the deceptive host phenotype hypothesis.

\section{REFERENCES}

Biere, A., and Tack, A. J. M. (2013). Evolutionary adaptation in three-way interactions between plants, microbes and arthropods. Funct. Ecol. 27, 646-660. doi: 10.1111/1365-2435.12096

Brown, M. W. (2011). Importance of early arrival of adult Harmonia axyridis for control of Aphis spiraecola on apple. BioControl 56, 65-69. doi: 10.1007/s10526010-9311-0

Cardoza, Y. J., Teal, P. E. A., and Tumlinson, J. H. (2003). Effect of peanut plant fungal infection on oviposition preference by Spodoptera exigua and on hostsearching behavior by Cotesia marginiventris. Environ. Entomol. 32, 970-976. doi: 10.1603/0046-225X-32.5.970

Cornet, S., Nicot, A., Rivero, A., and Gandon, S. (2013). Malaria infection increases bird attractiveness to uninfected mosquitoes. Ecol. Lett. 16, 323-329. doi: 10.1111/ele.12041

Davis, T. S., Horton, D. R., Munyaneza, J. E., and Landolt, P. J. (2012). Experimental infection of plants with an herbivore-associated bacterial endosymbiont influences herbivore host selection behavior. PLoS ONE 7:e49330. doi: 10.1371/journal.pone.0049330

Eigenbrode, S. D., Ding, H. J., Shiel, P., and Berger, P. H. (2002). Volatiles from potato plants infected with potato leafroll virus attract and arrest the virus vector, Myzus persicae (Homoptera: Aphididae). Proc. R. Soc. B. 269, 455-460. doi: 10.1098/rspb.2001.1909

Étienne, J., Quilici, S., Marival, D., and Franck, A. (2001). Biological control of Diaphorina citri (Hemiptera: Psyllidae) in Guadeloupe by imported
Tamarixia radiata (Hymenoptera: Eulophidae). Fruits 56, 307-315. doi: 10.1051/fruits:2001131

Finke, D. L. (2012). Contrasting the consumptive and non-consumptive cascading effects of natural enemies on vector-borne pathogens. Entomol. Exp. Appl. 144, 45-55. doi: 10.1111/j.1570-7458.2012.01258.x

Gomez-Torres, M. L., Nava, D. E., and Parra, J. R. P. (2012). Life table of Tamarixia radiata (Hymenoptera: Eulophidae) on Diaphorina citri (Hemipetra: Psyllidae) at different temperatures. J. Econ. Entomol. 105, 338-343. doi: 10.1603/ EC11280

Grafton-Cardwell, E. E., Stelinski, L. L., and Stansly, P. A. (2013). Biology and management of Asian citrus psyllid, vector of the huanglongbing pathogens. Annu. Rev. Entomol. 58, 413-432. doi: 10.1146/annurev-ento-120811-153542

Guerrieri E., Lingua G., Digilio M. C., Massa N., and Berta G. (2004). Do interactions between plant roots and the rhizosphere affect parasitoid behaviour? Ecol. Entomo. 29, 753-756 doi: 10.1111/j.0307-6946.2004.00644.x

Hall, D. G., and Albrigo, L. G. (2007). Estimating the relative abundance of flush shoots in citrus with implications on monitoring insects associated with flush. Hortscience 42, 364-368.

Landis, D. A., and van der Werf, W. (1997). Early-season predation impacts the establishment of aphids and spread of beet yellows virus in sugar beet. Entomophaga 2, 499-516. doi: 10.1007/BF02769810

Li, W. B., Hartung, J. S., and Levy, L. (2006). Quantitative real-time PCR for detection and identification of Candidatus Liberibacter species associated with citrus huanglongbing. J. Microbiol. Methods 66, 104-115. doi: 10.1016/j.mimet.2005.10.018

Mann, R. S., Ali, J. G., Hermann, S. L., Tiwari, S., Pelz-Stelinski, K. S., Alborn, H. T., et al. (2012). Induced release of a plant-defense volatile "deceptively" attracts insect vectors to plants infected with a bacterial pathogen. PLoS Pathog. 8:e1002610. doi: 10.1371/journal.ppat.1002610

Mann, R. S., Qureshi, J. A., Stansly, P. A., and Stelinski, L. L. (2010). Behavioral response of Tamarixia radiata (Waterston) (Hymenoptera: Eulophidae) to volatiles emanating from Diaphorina citri Kuwayama (Hemiptera: Psyllidae) and citrus. J. Insect Behav. 23, 447-458. doi: 10.1007/s10905-010-9228-6

Mann, R. S., Rouseff, R. L., Smoot, J. M., Castle, W. S., and Stelinski, L. L. (2011). Sulfur volatiles from Allium spp. affect Asian citrus psyllid, Diaphorina citri Kuwayama (Hemiptera: Psyllidae), response to citrus volatiles. B. Entomol. Res. 101, 89-97. doi: 10.1017/S0007485310000222

Mauck, K. E., Bosque-Perez, N. A., Eigenbrode, S. D., De Moraes, C. M., and Mescher, M. C. (2012). Transmission mechanisms shape pathogen effects on host-vector interactions: evidence from plant viruses. Funct. Ecol. 26, 1162 1175. doi: 10.1111/j.1365-2435.2012.02026.x

Mauck, K. E., De Moraes, C. M., and Mescher, M. C. (2010). Deceptive chemical signals induced by a plant virus attract insect vectors to inferior hosts. Proc. Natl. Acad. Sci. U.S.A. 107, 3600-3605. doi: 10.1073/pnas.0907191107

McLeod, G., Gries, R., von Rueuss, S. H., Rahe, J. E., McIntosh, R., Konig, W. A., et al. (2005). The pathogen causing Dutch elm disease makes host trees attract insect vectors. Proc. R. Soc. B. 272, 2499-2503. doi: 10.1098/rspb.2005.3202

Moore, S. M., Borer, E. T., and Hosseini, P. R. (2009). Predators indirectly control vector-borne disease: linking predator-prey and host pathogen models. J. R. Soc. Interface 7, 161-176. doi: 10.1098/rsif.2009.0131

Ngumbi, E., Eigenbrode, S. D., Bosque-Perez, N. A., Ding, H., and Rodriguez, A. (2007). Myzus persicae is arrested more by blends than by individual compounds elevated in headspace of PLRV-Infected potato. J. Chem. Ecol. 33, 1733-1747. doi: 10.1007/s10886-007-9340-Z

Okamoto, K. W., and Amarasekare, P. (2012). The biological control of disease vectors. J. Theor. Biol. 39, 47-57. doi: 10.1016/j.jtbi.2012.05.020

Patt, J. M., and Setamou, M. (2010). Responses of the Asian citrus psyllid to volatiles emitted by the flushing shoots of its rutaceous host plants. Environ. Entomol. 39, 618-624. doi: 10.1603/EN09216

Pelz-Stelinski, K. S., Brlansky, R. H., Ebert, T. A., and Rogers, M. E. (2010). Transmission parameters for Candidatus Liberibacter asiaticus by Asian citrus psyllid (Hemiptera: Psyllidae). J. Econ. Entomol. 103, 1531-1541. doi: 10.1603/EC10123

Pineda, A., Soler, R., Weldegergis, B. T., Shimwela, M. M., Van Loon, J. J. A., and Dicke, M. (2013). Non-pathogenic rhizobacteria interfere with the attraction of parasitoids to aphid-induced plant volatiles via jasmonic acid signalling. Plant Cell Environ. 36, 393-404. doi: 10.1111/j.1365-3040.2012.02581.x

Rodriguez-Saona, C., Kaplan, I., Braasch, J., Chinnasamy, D., and Williams, L. (2011). Field responses of predaceous arthropods to methyl salicylate: a 
meta-analysis and case study in cranberries. Biol. Control 59, 294-303. doi: 10.1016/j.biocontrol.2011.06.017

Rogers, M. E., and Bates, P. A. (2007). Leishmania manipulation of sand fly feeding behavior results in enhanced transmission. PLoS Pathog. 3:e91. doi: 10.1371/journal.ppat.0030091

Rostàs, M., Ton, J., Mauch-Mani, B., and Turlings, T. C. J. (2006). Fungal infection reduces herbivore-induced plant volatiles of maize but does not affect nave parasitoids. J. Chem. Ecol. 32, 1897-1909. doi: 10.1007/s10886-006-9147-3

Schröder, T.-W., and Basedow, T. (1999). Aphid attack, predators, infections by beet yellowing viruses and yields in fields of sugar beets with different insecticidal soil and seed treatments. J. Plant Dis. Protect. 106, 638-646.

Shapiro, L., De Moraes, C. M., Stephenson, A. G., and Mescher, M. C. (2012). Pathogen effects on vegetative and floral odours mediate vector attraction and host exposure in a complex pathosystem. Ecol. Lett. 15, 1430-1438. doi: 10.1111/ele.12001

Snoeren, T. A. L., Mumm, R., Poelman, E. H., Yang, Y., Pichersky, E., and Dicke, M. (2010). The herbivore-induced plant volatile methyl salicylate negatively affects attraction of the parasitoid Diadegma semiclausum. J. Chem. Ecol. 36, 479-89. doi: 10.1007/s10886-010-9787-1

Stelinski, L. L., Boina, D. R., and Meyer, W. L. (2010). Oviposition marking behavior of Diachasma alloeum, (Hymenoptera: Braconidae), parasitizing Rhagoletis pomonella, (Diptera: Tephritidae). J. Insect Behav. 23, 419-30. doi: 10.1007/s10905-010-9225-9

Tack, A. J. M., and Dicke, M. (2013). Plant pathogens structure arthropod communities across multiple spatial and temporal scales. Funct. Ecol. 27, 633-645. doi $10.1111 / 1365-2435.12087$

Tack, A. J. M., Gripenberg, S., and Roslin, T. (2012). Cross-kingdom interactions matter: fungal-mediated interactions structure an insect community on oak. Ecol. Lett. 15, 177-185. doi: 10.1111/j.1461-0248.2011.01724.x
Turlings, T. C., and Wäckers, F. (2004). "Recruitment of predators and parasitoids by herbivore-injuried plants" in Advances in Insect Chemical Ecology, eds R. T. Carde and G. M. Millar (Cambridge, UK: Cambridge University Press), 21-75.

van den Abbeele, J., Caljon, G., De Ridder, K., De Baetselier, P., and Coosemans, M. (2010). Trypanosoma brucei modifies the Tsetse salivary composition, altering the fly feeding behavior that favors parasite transmission. PLoS Pathog. 6:e1000926. doi: 10.1371/journal.ppat.1000926

Zar, J. H. (2009). Biostatisical Analysis, 5th Edn. (Upper Saddle River, NJ: Prentice Hall).

Conflict of Interest Statement: The authors declare that the research was conducted in the absence of any commercial or financial relationships that could be construed as a potential conflict of interest.

Received: 30 January 2014; paper pending published: 10 March 2014; accepted: 18 March 2014; published online: 29 May 2014.

Citation: Martini X, Pelz-Stelinski KS and Stelinski LL (2014) Plant pathogen-induced volatiles attract parasitoids to increase parasitism of an insect vector. Front. Ecol. Evol. 2:8. doi: $10.3389 /$ fevo.2014.00008

This article was submitted to Chemical Ecology, a section of the journal Frontiers in Ecology and Evolution.

Copyright (ㄷ) 2014 Martini, Pelz-Stelinski and Stelinski. This is an open-access article distributed under the terms of the Creative Commons Attribution License (CC BY). The use, distribution or reproduction in other forums is permitted, provided the original author(s) or licensor are credited and that the original publication in this journal is cited, in accordance with accepted academic practice. No use, distribution or reproduction is permitted which does not comply with these terms. 